\title{
Anticoagulant therapy during primary percutaneous coronary intervention for acute myocardial infarction: a meta-analysis of randomized trials in the era of stents and $\mathrm{P}_{2} \mathrm{Y}_{12}$ inhibitors
}

\author{
(c) (1) (8) OPEN ACCESS
}

Sripal Bangalore associate professor of medicine ${ }^{1}$, Bora Toklu fellow in cardiovascular prevention ${ }^{1}$, Anupam Kotwal resident in internal medicine ${ }^{2}$, Alexander Volodarskiy fellow in cardiovascular medicine ${ }^{1}$, Sahil Sharma resident in internal medicine ${ }^{3}$, Ajay J Kirtane assistant professor of

medicine ${ }^{4}$, Frederick Feit associate professor of medicine ${ }^{1}$

${ }^{1}$ New York University School of Medicine, New York, NY 10016, USA; ${ }^{2}$ University of Massachusetts, Worcester, MA, USA; ${ }^{3}$ Lincoln Medical Center, Bronx, NY, USA; ${ }^{4}$ Columbia University Medical Center/New York-Presbyterian Hospital, New York, NY, USA

\begin{abstract}
Objectives To investigate the relative benefits of unfractionated heparin, low molecular weight heparin(LMWH), fondaparinux, and bivalirudin as treatment options for patients with ST segment elevation myocardial infarction undergoing percutaneous coronary intervention (PCI).

Design Mixed treatment comparison and direct comparison meta-analysis of randomized trials in the era of stents and $\mathrm{P}_{2} \mathrm{Y}_{12}$ inhibitors.

Data sources and study selection A search of Medline, Embase, Cochrane Central Register of Controlled Trials (CENTRAL) for randomized trials comparing unfractionated heparin plus glycoprotein Illb/lla inhibitor(Gpllb/Illa inhibitor), unfractionated heparin, bivalirudin, fondaparinux, or LMWH plus Gpllb/llla inhibitor for patients undergoing primary PCl.
\end{abstract}

Outcomes The primary efficacy outcome was short term (in hospital or within 30 days) major adverse cardiovascular event; the primary safety outcome was short term major bleeding.

Results We identified 22 randomized trials that enrolled 22434 patients. In the mixed treatment comparison models, when compared with unfractionated heparin plus Gpllb/llla inhibitor, unfractionated heparin was associated with a higher risk of major adverse cardiovascular events (relative risk 1.49 (95\% confidence interval 1.21 to 1.84$)$, as were bivalirudin (relative risk 1.34 (1.01 to 1.78)) and fondaparinux (1.78 (1.01 to 3.14)). LMWH plus Gpllb/llla inhibitor showed highest treatment efficacy, followed (in order) by unfractionated heparin plus Gpllb/llla inhibitor, bivalirudin, unfractionated heparin, and fondaparinux. Bivalirudin was associated with lower major bleeding risk compared with unfractionated heparin plus Gpllb/lla inhibitor (relative risk $0.47(0.30$ to 0.74$)$ ) or unfractionated heparin $(0.58(0.37$ to 0.90$))$. Bivalirudin, followed by unfractionated heparin, LMWH plus Gpllb/llla inhibitor, unfractionated heparin plus Gpllb/llla inhibitor, and fondaparinux were the hierarchy for treatment safety. Results were similar in direct comparison meta-analyses: bivalirudin was associated with a 39\%, 44\%, and $65 \%$ higher risk of myocardial infarction, urgent revascularization, and stent thrombosis respectively when compared with unfractionated heparin with or without Gpllb/Illa inhibitor. However, bivalirudin was associated with a $48 \%$ lower risk of major bleeding compared with unfractionated heparin plus Gpllb/llla inhibitor and 32\% lower compared with unfractionated heparin alone.

Conclusions In patients undergoing primary $\mathrm{PCl}$, unfractionated heparin plus Gpllb/Illa inhibitor and LMWH plus Gpllb/Illa inhibitor were most efficacious, with the lowest rate of major adverse cardiovascular events, whereas bivalirudin was safest, with the lowest bleeding. These relationships should be considered in selecting anticoagulant therapies in patients undergoing primary $\mathrm{PCl}$.

\section{Introduction}

In patients with ST segment elevation myocardial infarction undergoing primary percutaneous coronary intervention (PCI), unfractionated heparin, low molecular weight heparin (LMWH), fondaparinux, and bivalirudin are all anticoagulant treatment options. The 2013 American College of Cardiology Foundation and American Heart Association guideline for management of 
patients with ST segment elevation myocardial infarction recommends unfractionated heparin with or without planned glycoprotein IIb/IIIa inhibitors (GpIIb/IIIa inhibitor) or bivalirudin as class I indications for patients undergoing primary PCI, with a preference for bivalirudin over unfractionated heparin plus GpIIb/IIIa inhibitor in patients at high risk of bleeding (class IIa). ${ }^{1}$ The 2012 European Society of Cardiology guidelines, however, recommend bivalirudin over unfractionated heparin plus GpIIb/IIIa inhibitor (class I) but also recommend LMWH (with or without GpIIb/IIIa inhibitor) over unfractionated heparin (class IIb).

The wide range of treatment options recommended in these guidelines stems from the broad comparative evidence base investigating the relative merits (both related to anti-ischemic efficacy and safety) of these respective therapies. Our objective was to evaluate systematically (using data from randomized trials) the ischemic and bleeding outcomes with various anticoagulant therapies in order to provide a hierarchy of treatment efficacy and safety in patients undergoing primary PCI for ST segment elevation myocardial infarction. In addition, to be relevant to contemporary practice, only randomized trials performed in the era of stents and $\mathrm{P} 2 \mathrm{Y}_{12}$ (ADP) receptor inhibitors were included.

\section{Methods \\ Eligibility criteria}

We searched PubMed, Embase, Cochrane Central Register of Controlled Trials (CENTRAL), Google Scholar, and the annual conference proceedings of the American Heart Association, American College of Cardiology, Society of Cardiovascular Angiography and Intervention, Transcatheter Cardiovascular Therapeutics, European Society of Cardiology, and Euro-PCR (the congress of the European Association of Percutaneous Cardiovascular Interventions) for randomized clinical trials comparing anticoagulant strategy in patients with ST segment elevation myocardial infarction undergoing primary PCI. The anticoagulant regimens searched were unfractionated heparin, LMWH, fondaparinux with or without GpIIb/IIIa inhibitor, and the direct thrombin inhibitor bivalirudin in patients undergoing primary PCI. The review was kept updated using automated weekly email alerts from PubMed. The MeSH terms are listed in the online supplementary table A, and the anticoagulants searched and their mechanism of action are listed in supplementary table B. We checked the reference lists of original studies, review articles, and meta-analyses identified by the electronic searches to find other eligible trials. There was no language restriction for the search.

Eligible randomized trials had to fulfill each of the following criteria: (1) trials comparing the above anticoagulant regimens in patients undergoing primary PCI; (2) trials enrolling subjects with ST segment elevation myocardial infarction with a sample size of $\geq 100$ patients; (3) trials with patients undergoing stent implantation and where $\mathrm{P}_{2} \mathrm{Y}_{12}$ inhibitors were used; and (4) trials reporting the outcomes of interest (see below). We excluded trials that included patients undergoing thrombolytic therapy for ST segment elevation myocardial infarction, patients undergoing facilitated or rescue PCI, or patients without ST segment elevation myocardial infarction.

\section{Selection and quality assessment}

Five authors (BT, SB, AV, AK, SS) independently assessed trial eligibility, extracted data, and evaluated trial bias risk. Disagreements were resolved by consensus. We used the trial risk of bias assessment scheme recommended by the Cochrane
Collaboration for quality assessment. ${ }^{3}$ The components of this risk assessment includes adequacy of sequence generation of the allocation; adequacy of allocation concealment; adequacy of blinding of participants, personnel, and outcome assessors; absence of incomplete outcome data; absence of selective outcome reporting; and other sources of bias. Risk assessments were performed using data from a number of sources (as available) including trial primary publications, trial design manuscript, trial protocol, and trial presentations. Trials with high or unclear risk for bias for any one of the first three components were considered as trials with high risk of bias. Otherwise, they were considered as trials with low risk of bias.

\section{Data extraction and synthesis}

Baseline demographics, trial design, antiplatelet therapy use, concomitant GpIIb/IIIa inhibitor use, access site for PCI, and outcomes data were extracted from each trial. For the purpose of this analysis, five treatment groups were identified: unfractionated heparin plus GpIIb/IIIa inhibitor, unfractionated heparin, bivalirudin, fondaparinux, and LMWH plus GpIIb/IIIa inhibitor. Trials where $>50 \%$ of patients received a GpIIb/IIIa inhibitor were considered as anticoagulant plus GpIIb/IIIa inhibitor trials. For example, in the ATOLL trial, $77 \%$ and $83 \%$ in the LMWH and unfractionated heparin groups also received GpIIb/IIIa inhibitor, and we considered them as LMWH plus GpIIb/IIIa inhibitor and unfractionated heparin plus GpIIb/IIIa inhibitor groups respectively. ${ }^{4}$ For the EUROMAX trial (bivalirudin $v$ unfractionated heparin with provisional GpIIb/IIIa inhibitor use), $69 \%$ of patients in the heparin group received GpIIb/IIIa inhibitor, and so this was considered as a trial of unfractionated heparin plus GpIIb/IIIa inhibitor in a sensitivity analysis. However, we used the recently presented data on outcomes of bivalirudin $v$ unfractionated heparin $v$ unfractionated heparin plus GpIIb/IIIa inhibitor from this trial for the main analysis. ${ }^{5}$ Of note, there were no trials that used LMWH alone, fondaparinux plus GpIIb/IIIa inhibitor, or bivalirudin plus GpIIb/IIIa inhibitor in patients undergoing primary PCI for ST segment elevation myocardial infarction.

\section{Study outcomes}

The primary efficacy outcome was short term (in hospital or within 30 days) ischemic events-major adverse cardiovascular event (composite of death, myocardial infarction, urgent target vessel or lesion revascularization, or stroke). Other short term ischemic outcomes evaluated were death, myocardial infarction, urgent revascularization, and stent thrombosis tabulated separately. The primary safety outcome was short term major bleeding, while the secondary outcome was minor bleeding, both as defined in each individual trial. The individual trial definitions of outcomes are outlined in supplementary table D.

\section{Statistical analyses \\ Mixed treatment comparisons}

The primary analysis compared each treatment group against the unfractionated heparin plus GpIIb/IIIa inhibitor group, which was chosen as the reference group. Other pairwise comparisons were also performed to assess all other possible comparators using a mixed treatment comparison or network analysis. Mixed treatment comparison allows for synthesis of direct and indirect evidence from a network of trials that compare different interventions by incorporating the indirect comparisons constructed from two trials that have one intervention in common (such as comparison of anticoagulant regimen $\mathrm{A} v \mathrm{C}$ using trials comparing $\mathrm{A} v \mathrm{~B}$ and $\mathrm{B} v \mathrm{C}$ ). Network meta-analysis 
was performed using a frequentist based approach with the use of multivariate, random effects meta-analysis. ${ }^{67}$ The weight of each direct comparison is proportional to the variance of the observed effect and the network structure. Multivariate meta-analysis was used to estimate the within-study correlations and to estimate the relative treatment effects, their variance and covariance. ${ }^{8}$ The covariance between two estimates from the same study (sharing a common treatment group) is the variance of the data in the shared arm and is calculated using the multivariate meta-analysis method. Inconsistency in a network model was estimated using the inconsistency factors (the difference between direct and indirect treatment effect estimates) and their uncertainty (using loops specific heterogeneity estimates).

The presence of small-study effect was assessed using a "comparison-adjusted" funnel plot, which takes into account different summary effect for each set of studies (measure of precision $v$ estimated treatment effect). ${ }^{9}$ The horizontal axis is the study-specific effect sizes centered to the respective comparison-specific pooled effect size while the vertical axis is the inverted standard error of the effect sizes as used in a standard funnel plot. If all studies are lying symmetrically around the zero line the comparison-adjusted funnel plot suggests no evidence of small-study effects in the network. ${ }^{9}$ In addition, ranking plots (rankograms) were constructed using probabilities (and their uncertainty in relative treatment effects) that a given treatment had the lowest event rate for each outcome. A rankogram for a specific treatment, such as bivalirudin, is a plot of the probability of bivalirudin assuming each of the possible ranks (rank 1 through to 5). In addition a cumulative rankogram, which present the probabilities that a treatment would be among the best treatments was also constructed. The surface under the cumulative ranking curve (SUCRA), which is a simple transformation of the mean rank, was used to provide a hierarchy of the treatments. ${ }^{10}$ The larger the SUCRA value, the higher the rank of the treatment. ${ }^{10}$ In addition, clustered ranking plot was constructed using SUCRA values for efficacy (major adverse cardiovascular event) and safety (major bleeding) outcomes to obtain information on meaningful groups of treatments that maximize benefit for both ischemic and bleeding outcomes. The probability was estimated under a Bayesian model with flat priors (that is, similar to frequentist estimates) using 10000 replicates to minimize Monte Carlo error.

\section{Direct comparison meta-analysis}

In addition to network meta-analysis, a direct comparison meta-analysis was performed using data for the closed loop in the network analysis (that is, trials comparing bivalirudin versus unfractionated heparin with or without GpIIb/IIIa inhibitor). Intention-to-treat meta-analyses were performed in line with recommendations from the Cochrane Collaboration and the Preferred Reporting Items for Systematic Reviews and Meta-Analyses (PRISMA) statement. ${ }^{3}{ }^{31}$ Heterogeneity was assessed using the $\mathrm{I}^{2}$ statistic, ${ }^{12}{ }^{13}$ which is the proportion of total variation observed between the trials attributable to differences between trials rather than sampling error (chance), with $\mathrm{I}^{2}<25 \%$ considered low and $\mathrm{I}^{2}>75 \%$ high. Summary effect sizes and the $95 \%$ confidence intervals were calculated using both the random-effects model of DerSimonian and Laird and the fixed-effect model.$^{13}$ Bias was estimated visually by funnel plots and using Begg's test and the weighted regression test of Egger. ${ }^{14}$ Meta regression was performed to evaluate the role of access site (percentage of transradial procedures) and newer $\mathrm{P} 2 \mathrm{Y}_{12}$ use (percentage of patients receiving either prasugrel or ticagrelor) on the risk of major bleeding. Similarly, meta-regression analysis was performed to evaluate the role of newer $\mathrm{P} 2 \mathrm{Y}_{12}$ use on the risk of major adverse cardiovascular event.

All analyses were performed using standard software (Stata 12.0, Stata Corporation, Texas). $\mathrm{P}<0.05$ was used to denote statistical significance.

\section{Sensitivity analysis}

Various sensitivity analyses were conducted to assess the robustness of the results. Analyses were performed $(a)$ based on trial quality; $(b)$ considering the EUROMAX trial as a trial of unfractionated heparin plus GpIIb/IIIa inhibitor; and (c) using a restricted network comparing unfractionated heparin plus GpIIb/IIIa inhibitor, unfractionated heparin, and bivalirudin and excluding trials comparing LMWH plus GpIIb/IIIa inhibitor and fondaparinux.

\section{Results \\ Study selection and characteristics of included trials}

We identified 22 randomized trials that satisfied the inclusion criteria and enrolled a total of 22434 patients (supplementary fig 1). The network of treatment comparisons are shown in figure $1 \Downarrow$. One trial was a three-arm trial while the rest were two-arm trials. The baseline characteristics of the included trials are presented in supplementary tables C and D.

\section{Efficacy outcomes Major adverse cardiovascular event}

In the mixed treatment comparison models, with data from 21 randomized trials and 22271 patients and 1386 events, when compared with unfractionated heparin plus GpIIb/IIIa inhibitor (reference relative risk 1.0), unfractionated heparin was associated with higher risk of major adverse cardiovascular event (relative risk 1.49 (95\% confidence interval 1.21 to 1.84 )), as were bivalirudin (relative risk 1.34 (1.01 to 1.78$)$ ) and fondaparinux (relative risk 1.78 (1.01 to 3.14 )) (fig $2 \Downarrow$ ). Similarly, when compared with LMWH plus GpIIb/IIIa inhibitor, unfractionated heparin was associated with a higher risk of major adverse cardiovascular event (relative risk 2.56 (1.30 to 5.00)), as were bivalirudin (relative risk 2.27 (1.15 to 4.54)) and fondaparinux (relative risk 3.03 (1.30 to 7.14)) (fig 2). In the probability analysis the hierarchy for treatment efficacy for major adverse cardiovascular event (highest to lowest rank) was LMWH plus GpIIb/IIIa inhibitor, followed by unfractionated heparin plus GpIIb/IIIa inhibitor, bivalirudin, unfractionated heparin, and fondaparinux (supplementary fig 2). There was no evidence of statistical inconsistency between direct and indirect estimates $(\mathrm{P}=0.11)$.

\section{Death}

In the mixed treatment comparison models, with data from 21 randomized trials with 21561 patients and 705 events, when compared with unfractionated heparin plus GpIIb/IIIa inhibitor as reference, there were no statistically significant increases in death with other agents (fig $2 \Downarrow$ ). However, there was lower mortality with LWMH plus GpIIb/IIIa inhibitor when compared with unfractionated heparin (relative risk 0.45 (0.21 to 0.95$)$ ) and with fondaparinux (relative risk 0.39 (0.16 to 0.97)) (fig 2). In the probability analysis the hierarchy for treatment efficacy for death (highest to lowest rank) was LMWH plus GpIIb/IIIa inhibitor, followed by unfractionated heparin plus GpIIb/IIIa inhibitor, bivalirudin, unfractionated heparin, and fondaparinux 
(supplementary fig 3). There was no evidence of statistical inconsistency between direct and indirect estimates $(\mathrm{P}=0.06)$.

\section{Myocardial infarction}

In the mixed treatment comparison models, with data from 21 randomized trials with 21561 patients and 353 events, when compared with unfractionated heparin plus GpIIb/IIIa inhibitor, the point estimates for unfractionated heparin, bivalirudin, and fondaparinux all favored unfractionated heparin plus GpIIb/IIIa inhibitor (fig $2 \Downarrow$ ). When compared with LMWH plus GpIIb/IIIa inhibitor, bivalirudin was associated with a significant increase in myocardial infarction (relative risk 2.94 (1.04 to 8.33)) (fig 2). In the probability analysis the hierarchy for treatment efficacy for myocardial infarction (highest to lowest rank) was LMWH plus GpIIb/IIIa inhibitor, followed by unfractionated heparin plus GpIIb/IIIa inhibitor, unfractionated heparin, fondaparinux, and bivalirudin (supplementary fig 4). There was no evidence of statistical inconsistency between direct and indirect estimates $(\mathrm{P}=0.22)$.

\section{Revascularization}

In the mixed treatment comparison models, with data from 20 randomized trials with 17772 patients and 394 events, when compared with unfractionated heparin plus GpIIb/IIIa inhibitor, unfractionated heparin was associated with a significant increase in revascularization (relative risk 1.42 (1.04 to 1.92)), as was bivalirudin (relative risk 1.60 (1.09 to 2.35)) (fig $2 \Downarrow$ ). There was no data available for fondaparinux. In the probability analysis the hierarchy for treatment efficacy for revascularization was (highest to lowest rank) LMWH plus GpIIb/IIIa inhibitor, followed by unfractionated heparin plus GpIIb/IIIa inhibitor, unfractionated heparin, and bivalirudin (supplementary fig 5). There was no evidence of statistical inconsistency between direct and indirect estimates $(\mathrm{P}=0.20)$.

\section{Stent thrombosis}

In the mixed treatment comparison models, with data from 11 randomized trials with 14949 patients and 209 events, when compared with unfractionated heparin plus GpIIb/IIIa inhibitor, bivalirudin was associated with a significant increase in stent thrombosis (relative risk 2.34 (1.03 to 5.32)) (fig $2 \Downarrow$ ). There was no data available for fondaparinux. In the probability analysis the hierarchy for treatment efficacy for stent thrombosis (highest to lowest rank) was unfractionated heparin plus GpIIb/IIIa inhibitor followed by LMWH plus GpIIb/IIIa inhibitor, unfractionated heparin, and bivalirudin (supplementary fig 6).

\section{Bleeding outcomes Major bleeding}

In the mixed treatment comparison models, with data from 21 randomized trials with 21561 patients and 547 events, bivalirudin was associated with lower major bleeding when compared with unfractionated heparin plus GpIIb/IIIa inhibitor (relative risk 0.47 ( 0.30 to 0.74$)$ ) or with unfractionated heparin alone (relative risk $0.58(0.37$ to 0.90$)$ ) (fig $3 \Downarrow)$. In the probability analysis the hierarchy for treatment safety for major bleeding rate was (highest to lowest) bivalirudin, followed by unfractionated heparin, LMWH plus GpIIb/IIIa inhibitor, unfractionated heparin plus GpIIb/IIIa inhibitor, and fondaparinux (supplementary fig 7). There was no evidence of statistical inconsistency between direct and indirect estimates $(\mathrm{P}=0.69)$.

\section{Minor bleeding}

In the mixed treatment comparison models, with data from 15 randomized trials with 16508 patients and 1031 events, when compared with unfractionated heparin plus GpIIb/IIIa inhibitor, unfractionated heparin was associated with a decrease in minor bleeding (relative risk 0.67 (0.52 to 0.86$)$ ), as was bivalirudin (relative risk $0.56(0.43$ to 0.74$)$ ) (fig $3 \Downarrow$ ). There was no data available for fondaparinux. There was no statistically significant difference in minor bleeding with bivalirudin when compared with unfractionated heparin alone (relative risk 0.84 ( 0.63 to $1.12)$ ). In the probability analysis the hierarchy for treatment safety for minor bleeding was (highest to lowest rank) bivalirudin, followed by unfractionated heparin, LMWH plus GpIIb/IIIa inhibitor, and unfractionated heparin plus GpIIb/IIIa inhibitor (supplementary fig 8). There was no evidence of statistical inconsistency between direct and indirect estimates $(\mathrm{P}=0.64)$.

There was no evidence of small-study effect in any of the models (supplementary fig 9).

\section{Sensitivity analysis}

The results were largely similar in a sensitivity analysis based on trial quality and when the EUROMAX data was considered as a comparison trial of unfractionated heparin plus GpIIb/IIIa inhibitor (data not shown). In the restricted network of unfractionated heparin plus GpIIb/IIIa inhibitor, unfractionated heparin, and bivalirudin comparison trials alone, the results were largely similar, with higher risk of major adverse cardiovascular event with bivalirudin (relative risk 1.34 (1.01 to 1.79 )) and unfractionated heparin (relative risk 1.42 (1.21 to 1.84)) when compared with unfractionated heparin plus GpIIb/IIIa inhibitor. The hierarchy (highest to lowest rank) for treatment efficacy for major adverse cardiovascular event was unfractionated heparin plus GpIIb/IIIa inhibitor followed by bivalirudin and then unfractionated heparin.

Similarly, bivalirudin was associated with increased urgent revascularization (relative risk 1.61 (1.09 to 2.37)) and stent thrombosis (relative risk 3.04 (1.13 to 8.17)), and unfractionated heparin was associated with increased urgent revascularization (relative risk 1.42 (1.04 to 1.93)) and numerically higher stent thrombosis (relative risk 2.26 (0.94 to 5.46)) when compared with unfractionated heparin plus GpIIb/IIIa inhibitor. The hierarchy (highest to lowest rank) for treatment efficacy for urgent revascularization and stent thrombosis was unfractionated heparin plus GpIIb/IIIa inhibitor followed by unfractionated heparin and then bivalirudin.

There was no statistically significant difference in death or myocardial infarction between the three comparison groups. For safety outcomes, bivalirudin was associated with lower major bleeding compared with unfractionated heparin plus GpIIb/IIIa inhibitor (relative risk 0.47 (0.30 to 0.75$)$ ) or with unfractionated heparin (relative risk 0.58 (0.37 to 0.90$)$ ). The hierarchy (highest to lowest rank) for treatment safety for major bleeding was bivalirudin followed by unfractionated heparin and then unfractionated heparin plus GpIIb/IIIa inhibitor.

\section{Direct comparison (bivalirudin $v$ unfractionated heparin or unfractionated heparin plus Gpllb/llla inhibitor)}

For the efficacy outcomes, in the direct comparison meta-analysis, there was no statistically significant difference between bivalirudin and unfractionated heparin (with or without GpIIb/IIIa inhibitor) for major adverse cardiovascular event (event rate $5.94 \% v 5.48 \%$ ) (fig $4 \Downarrow$ ) or death (event rate $2.71 \%$ 
$v 2.95 \%$ ) (fig 4). However, bivalirudin was associated with a $39 \%$ increase in myocardial infarction (event rate $1.70 \% \mathrm{v}$ $1.24 \%$ ) (fig $5 \Downarrow$ ), a $44 \%$ increase in urgent revascularization (event rate $2.22 \% v 1.55 \%$ ) (fig $5 \Downarrow$ ), and an $65 \%$ increase in stent thrombosis (event rate $1.63 \% v 1.02 \%$ ) (fig $5 \Downarrow$ ) when compared with unfractionated heparin with or without GpIIb/IIIa inhibitor. The test for interaction for the subgroups was not significant $\left(\mathrm{P}_{\text {interaction }}>0.05\right)$, indicating similar effect of bivalirudin for the above outcomes when compared with unfractionated heparin plus GpIIb/IIIa inhibitor or compared with unfractionated heparin alone.

For safety outcomes, bivalirudin was associated with a $48 \%$ decrease in major bleeding compared with unfractionated heparin plus GpIIb/IIIa inhibitor (event rate $2.40 \%$ v $4.53 \%$ ), $32 \%$ decrease in major bleeding compared with unfractionated heparin (event rate $2.36 \% v 3.19 \%$ ) (fig $6 \Downarrow$ ), a $47 \%$ decrease in minor bleeding compared with unfractionated heparin plus GpIIb/IIIa inhibitor (event rate $4.08 \%$ v $7.72 \%$ ), and numerically lower minor bleeding compared with unfractionated heparin alone (event rate $6.97 \% v 8.44 \%$ ) (fig $6 \Downarrow$ ). There was low to moderate heterogeneity in the above analyses without evidence of small-study effect.

Meta-regression analysis evaluating the relationship between newer P2 $\mathrm{Y}_{12}$ inhibitor use (supplementary fig 10) or access site (supplementary fig 11) and risk of major bleeding with bivalirudin did not show any statistically significant results ( $\mathrm{P}=0.47$ and $\mathrm{P}=0.38$ respectively), although the regression line showed a trend towards less benefit with bivalirudin for major bleeding with increasing newer P2Y12 inhibitor use or greater percentage of patients undergoing transradial intervention. Similarly, meta-regression analysis evaluating the relationship between newer P2Y12 inhibitor use and risk of major adverse cardiovascular event with bivalirudin did not show any statistically significant results $(\mathrm{P}=0.61)$ (supplementary fig 12$)$.

\section{Discussion}

The results of the present study with data derived from more than 22000 patients from randomized trials reveals the challenges of a "one size fits all" approach to anticoagulant therapy for patients undergoing primary percutaneous coronary intervention (PCI) for acute myocardial infarction by demonstrating that anticoagulant regimens have variable effects on efficacy and safety outcomes. In the present analysis, LMWH plus GpIIb/IIIa inhibitor or unfractionated heparin plus GpIIb/IIIa inhibitor were the most efficacious agents with the lowest risk for ischemic outcomes, but this occurred at the expense of an increase in bleeding. Bivalirudin, on the other hand, was the safest agent with the lowest risk of bleeding, but this occurred at the expense of increase in ischemic outcomes including recurrent myocardial infarction, revascularization, and stent thrombosis - results that were consistent in the network model, in the direct comparison meta-analyses, and in the various sensitivity analyses performed. Of note, the data for LMWH were based on one trial only.

\section{Anticoagulation for primary $\mathbf{P C I}$}

In patients presenting with ST segment elevation myocardial infarction, a heightened state of inflammation and thrombosis, prevention of repeat ischemic events (recurrent myocardial infarction or stent thrombosis) is important. In addition, patients presenting with ST segment elevation myocardial infarction are also at increased risk of iatrogenic bleeding complications due to the administration of potent anticoagulant and antiplatelet therapies aimed at passivating the pro-thrombotic state. Notably, both ischemic and bleeding outcomes have long term adverse prognostic significance, making prevention of both of paramount importance. The choice of optimal anticoagulant therapy for primary PCI is therefore of considerable interest and has been tested in several clinical trials. Several different agents are currently available, each with different mode of action with strengths and limitations.

Unfractionated heparin acts by binding to and activating antithrombin III, which inactivates thrombin and factor Xa and thus acts as an indirect thrombin inhibitor. However, unfractionated heparin has many limitations including limited action on clot-bound thrombin, increase in platelet activation and aggregation, unpredictable anticoagulant response, and risk of heparin induced thrombocytopenia. The efficacy and safety of unfractionated heparin plus GpIIb/IIIa inhibitor when compared with unfractionated heparin alone has been tested in several randomized trials. In an analysis of 16 randomized trials in the era of stents and thienopyridines, unfractionated heparin plus GpIIb/IIIa inhibitor were associated with a $26 \%$ reduction in the risk of myocardial infarction and $36 \%$ reduction in revascularization at the expense of a $37 \%$ increase in minor bleeding when compared with unfractionated heparin alone. ${ }^{15}$ Our analyses were largely concordant, where unfractionated heparin plus GpIIb/IIIa inhibitor was associated with a 33\% reduction in major adverse cardiovascular events, $30 \%$ reduction in urgent revascularization, and numerically lower myocardial infarction (trend towards $23 \%$ decrease) and stent thrombosis (trend towards 50\% decrease) at the expense of $49 \%$ increase in minor bleeding and numerically higher major bleeding (trend towards $22 \%$ increase) when compared with unfractionated heparin alone.

LMWH also binds to antithrombin III and inactivates factor Xa but with less effect on thrombin. Compared with unfractionated heparin, LMWH has a longer half life, less propensity to cause heparin induced thrombocytopenia, and, in a few studies, causes less bleeding. ${ }^{16}$ In the ATOLL trial comparing intravenous LMWH (enoxaparin) with unfractionated heparin in patients undergoing primary PCI, LMWH resulted in a $41 \%$ reduction in ischemic outcomes (composite of death, recurrent acute coronary syndrome, and urgent revascularization or composite of death and complication of myocardial infarction) without any increase in bleeding endpoints when compared with unfractionated heparin. ${ }^{4}$

Fondaparinux is a synthetic pentasaccharide inhibitor of factor Xa with substantially lower risk of heparin induced thrombocytopenia. In patients with acute coronary syndromes, fondaparinux is similar to enoxaparin in reducing the risk of ischemic events, but it also substantially reduces major bleeding and improves long term mortality and morbidity. ${ }^{17}$ However, in the OASIS- 6 trial, in the subgroup of patients undergoing primary PCI, fondaparinux was not associated with any benefit compared with unfractionated heparin and was associated with an increased risk of catheter thrombosis. ${ }^{18}$

Bivalirudin is a direct thrombin inhibitor that works effectively on both circulating and clot-bound thrombin, with less activation of platelets and does not cause heparin induced

thrombocytopenia. It has been consistently shown to reduce the risk of bleeding in randomized trials. In the HORIZONS-AMI trial, bivalirudin was associated with a significantly lower 30 day rate of major bleeding but significant increase in acute stent thrombosis compared with unfractionated heparin plus GpIIb/IIIa inhibitor. ${ }^{19}$ This and other trials in patients with acute coronary syndromes led to rapid upgrading of both national and international recommendations for the use of bivalirudin for primary PCI. In the EUROMAX trial ${ }^{5}$ patients who were being 
transported for primary PCI were randomized to receive either bivalirudin or heparin with optional GpIIb/IIIa inhibitor.

Bivalirudin was associated with a substantial reduction in death or major bleeding, the composite of death, reinfarction, and non-CABG major bleeding, and major bleeding alone, but was associated with significant increase in the risk of stent thrombosis. However, in both of the above trials there was differential use of GpIIb/IIIa inhibitor in both randomized treatment arms. For example, in the EUROMAX trial, $69 \%$ of the heparin group received GpIIb/IIIa inhibitor (compared with $11.9 \%$ of the bivalirudin group). Therefore it is not clear if the bleeding advantage seen with bivalirudin is a reflection of this differential use of GpIIb/IIIa inhibitor.

In the HEAT PPCI trial, designed to minimize differential GpIIb/IIIa inhibitor use, bivalirudin was compared against unfractionated heparin, both with bailout GpIIb/IIIa inhibitor. There was similar GpIIb/IIIa inhibitor use in both arms. Bivalirudin was associated with an increase in the primary ischemic outcome driven by an increase in recurrent myocardial infarction, revascularization, and stent thrombosis with no benefit for major bleeding. ${ }^{20}$ Of note, in the current analysis, the increase in stent thrombosis with bivalirudin when compared with unfractionated heparin alone was only seen in the fixed effect model of the direct comparison analysis but was not statistically significant in the random effects model as well as in the mixed treatment comparison analyses. Similarly, in the BRAVE 4 trial of patients with ST segment elevation myocardial infarction who were randomized to bivalirudin with prasugrel versus unfractionated heparin with clopidogrel, there was low and similar use of GpIIb/IIIa inhibitor in both arms. There was no advantage of bivalirudin for any bleeding or ischemic endpoints in this prematurely terminated, underpowered trial. ${ }^{21}$ It is not clear if the lack of a bleeding advantage with bivalirudin in more recent studies are due to comparison against agents with less bleeding potential (unfractionated heparin alone), due to reduction in access site bleeding because of greater use of transradial procedures and closure devices, or due to potential negation of the bleeding advantage with use of more potent antiplatelet agents such as prasugrel, or a combination of all of the above factors.

In the present analysis we demonstrated that the combination of an indirect thrombin inhibitor with a GpIIb/IIIa inhibitor (unfractionated heparin plus GpIIb/IIIa inhibitor and LMWH plus GpIIb/IIIa inhibitor) were associated with the lowest rate of ischemic outcomes. However, there was an increase in bleeding with these agents. On the other hand, bivalirudin was associated with a significant reduction in bleeding but a significant increase in ischemic outcomes, including stent thrombosis. So how then should we choose anticoagulant therapies in patients undergoing primary PCI? Figure $7 \Downarrow$ shows a plot of the cumulative ranking data for both ischemic and bleeding outcomes. The ideal anticoagulant therapy choice would be one with the bleeding advantage of bivalirudin and the reduced ischemic rates associated with an indirect thrombin inhibitor with GpIIb/IIIa inhibitor use. Unfortunately, currently there is no ideal agent that would maximize benefit for both ischemic and bleeding endpoints (fig 7). The choice of therapy should therefore be individualized, weighing the risks of bleeding against the risk of ischemic outcomes. Whether the incorporation of newer and more potent oral or parenterally administered adjunctive antiplatelet therapies in conjunction with these agents can further optimize the anticoagulant regimen remains an area of investigation. Of note, the data on LMWH and the data for fondaparinux are based on one randomized trial each and should be interpreted with caution.
Although the randomized trials included in the current analysis are the only randomized trials available to guide decision making, these trials have several limitations in relation to current day practice of primary PCI, which has evolved with greater use of more potent antiplatelet agents (higher dose of clopidogrel or novel $\mathrm{P} 2 \mathrm{Y}_{12}$ inhibitors), greater use of second generation drug eluting stents (shown to have a low risk of stent thrombosis), and transradial access and use of vascular closure devices for femoral access (both of which reduce bleeding), all of which can significantly affect both the ischemic and bleeding outcomes.

The evolution of guidelines and practice patterns in the US and elsewhere are to move towards bivalirudin as the anticoagulant of choice and to use unfractionated heparin plus GpIIb/IIIa inhibitor rarely. LMWH is rarely used in PCI patients. The result of the present study questions current practices and provides a thorough hierarchical analysis of the relative efficacy and safety of currently used anticoagulants for physicians to make a rational decision based on patients risk of bleeding versus thrombotic events. In other words, a "one size fits all" approach may not be wise.

The 2014 European Society of Cardiology and European Association for Cardio-Thoracic Surgery guidelines on myocardial revascularization downgraded the recommendation for bivalirudin from class I to IIa in patients with ST segment elevation myocardial infarction undergoing PCI. ${ }^{22}$ The considerations for anticoagulation choice in contemporary practice are outlined in the table $\Downarrow$.

\section{Study limitations}

As in other meta-analyses, given the lack of consistently reported data in each trial, we did not adjust our analyses for any study-specific or treatment-specific covariates such as choice of access site, $\mathrm{P} 2 \mathrm{Y}_{12}$ inhibitor use, dose and timing of $\mathrm{P} 2 \mathrm{Y}_{12}$ inhibitor administration, dose and duration of anticoagulant therapy during and after PCI, or the type of stent used (all of which might have significant impact on bleeding and ischemic endpoints). Although meta-regression analyses were performed to evaluate the relationship of novel $\mathrm{P} 2 \mathrm{Y}_{12}$ inhibitor use and access site on the risk of major adverse cardiovascular event and major bleeding with bivalirudin, these results are likely underpowered. In addition, none of the studies were blinded, only one study assessed LMWH, one large trial was based at a single center (HEAT PPCI), and trials classified as heparin plus $\mathrm{GpIIb/IIIa} \mathrm{inhibitor} \mathrm{had} \mathrm{variable} \mathrm{rates} \mathrm{of} \mathrm{GpIIb/IIIa} \mathrm{inhibitor}$ use. Moreover, even though the follow-up assessed was short term, the reported time point varied from seven to 30 days. The definitions of endpoints and especially that for bleeding varied. Moreover, the BRAVE-4 trial was terminated early because of slow recruitment. Nevertheless, the current study provides important insights into the short term bleeding and ischemic outcomes with various anticoagulant regimens. There was consistency in the results from both the network models and the direct comparison analyses with lack of a small-study effect.

\section{Conclusions}

In patients with ST segment elevation myocardial infarction undergoing primary PCI, the currently available anticoagulant therapy choices have a trade-off between bleeding and ischemic outcomes such that LMWH plus GpIIb/IIIa inhibitor and unfractionated heparin plus GpIIb/IIIa inhibitor were the most efficacious with the lowest ischemic rates but increased bleeding, whereas bivalirudin was safest with lowest bleeding rate at the expense of an increase in ischemic outcomes. These 
data should be considered in the choice of anticoagulant therapy for patients undergoing primary PCI.

Contributors: SB had full access to all of the data in the study and takes responsibility for the integrity of the data and the accuracy of the data analysis. SB was responsible for study concept and design, drafting of the manuscript, statistical analysis, and study supervision. SB, BT, AV, $\mathrm{SS}$, and $\mathrm{AK}$ acquired the data. SB, BT, AJK, and FF undertook analysis and interpretation of data. SB, BT, AV, SS, AK, FF, and AJK critically revised the manuscript for important intellectual content.

Funding: This research received no specific grant from any funding agency in the public, commercial, or not-for-profit sectors.

Competing interests: All authors have completed the ICMJE uniform disclosure form at www.icmje.org/coi_disclosure.pdf (available on request from the corresponding author) and declare: no support from any organisation for the submitted work; no financial relationships with any organizations that might have an interest in the submitted work in the previous three years; no other relationships or activities that could appear to have influenced the submitted work.

Ethical approval: Not required.

Data sharing: No additional data available.

Transparency: The lead author (the manuscript's guarantor) affirms that the manuscript is an honest, accurate, and transparent account of the study being reported; no important aspects of the study have been omitted; and any discrepancies from the study as planned (and, if relevant, registered) have been explained.

1 O'Gara PT, Kushner FG, Ascheim DD, Casey DE, Jr., Chung MK, de Lemos JA, et al. 2013 ACCF/AHA guideline for the management of ST-elevation myocardial infarction: executive summary: a report of the American College of Cardiology Foundation/American Heart Association Task Force on Practice Guidelines. Circulation 2013;127:529-55.

2 Task Force on the management of ST-segment elevation acute myocardial infarction of the European Society of Cardiology (ESC), Steg PG, James SK, Atar D, Badano LP, Blömstrom-Lundqvist $\mathrm{C}$, et al. ESC guidelines for the management of acute myocardial infarction in patients presenting with ST-segment elevation. Eur Heart J 2012;33:2569-619.

3 Higgins J, Green S. Cochrane handbook for systematic reviews of interventions. Version 5.0.0. Cochrane Collaboration, 2008. www.cochrane-handbook.org.

4 Montalescot G, Zeymer U, Silvain J, Boulanger B, Cohen M, Goldstein P, et al. Intravenous enoxaparin or unfractionated heparin in primary percutaneous coronary intervention for ST-elevation myocardial infarction: the international randomised open-label ATOLL trial. Lancet 2011;378:693-703.

5 Steg PG, van 't Hof A, Hamm CW, Clemmensen P, Lapostolle F, Coste P, et al. Bivalirudin started during emergency transport for primary PCI. N Engl J Med 2013;369:2207-17.

$6 \quad$ Higgins JPT, Jackson D, Barrett JK, Lu G, Ades AE, White IR. Consistency and inconsistency in network meta-analysis: concepts and models for multi-arm studies. Research Synthesis Methods 2012;3:98-110.
7 White IR, Barrett JK, Jackson D, Higgins JPT. Consistency and inconsistency in network meta-analysis: model estimation using multivariate meta-regression. Research Synthesis Methods 2012;3:111-25

8 White I. Multivariate random-effects meta-analysis. Stata J 2009;9:40-56

9 Chaimani A, Higgins JP, Mavridis D, Spyridonos P, Salanti G. Graphical tools for network meta-analysis in STATA. PLoS One 2013;8:e76654.

10 Salanti G, Ades AE, loannidis JP. Graphical methods and numerical summaries for presenting results from multiple-treatment meta-analysis: an overview and tutorial. $J$ Clin Epidemiol 2011;64:163-71.

11 Moher D, Cook DJ, Eastwood S, Olkin I, Rennie D, Stroup DF. Improving the quality of reports of meta-analyses of randomised controlled trials: the QUOROM statement. Quality of Reporting of Meta-analyses. Lancet 1999;354:1896-900.

12 Galbraith RF. A note on graphical presentation of estimated odds ratios from several clinical trials. Stat Med 1988;7:889-94.

13 DerSimonian R, Laird N. Meta-analysis in clinical trials. Control Clin Trials 1986;7:177-88

14 Egger M, Davey Smith G, Schneider M, Minder C. Bias in meta-analysis detected by a simple, graphical test. BMJ 1997;315:629-34

15 Winchester DE, Brearley WD, Wen X, Park KE, Bavry AA. Efficacy and safety of unfractionated heparin plus glycoprotein Ilb/llla inhibitors during revascularization for an acute coronary syndrome: a meta-analysis of randomized trials performed with stents and thienopyridines. Clin Cardiol 2012;35:93-100.

16 Li WM, Yang XC, Wang LF, Ge YG, Wang HS, Xu L, et al. Comparison of tirofiban combined with dalteparin or unfractionated heparin in primary percutaneous coronary intervention of acute ST-segment elevation myocardial infarction patients. Chin Med J (Engl) 2011;124:3275-80.

17 Fifth Organization to Assess Strategies in Acute Ischemic Syndromes I, Yusuf S, Mehta SR, Chrolavicius S, Afzal R, Pogue J, et al. Comparison of fondaparinux and enoxaparin in acute coronary syndromes. N Engl J Med 2006;354:1464-76.

18 Yusuf S, Mehta SR, Chrolavicius S, Afzal R, Pogue J, Granger CB, et al. Effects of fondaparinux on mortality and reinfarction in patients with acute ST-segment elevation myocardial infarction: the OASIS-6 randomized trial. JAMA 2006;295:1519-30.

19 Stone GW, Witzenbichler B, Guagliumi G, Peruga JZ, Brodie BR, Dudek D, et al. Bivalirudin during primary PCl in acute myocardial infarction. N Engl J Med 2008;358:2218-30.

20 Shahzad A, Kemp I, Mars C, Wilson K, Roome C, Cooper R, et al. Unfractionated heparin versus bivalirudin in primary percutaneous coronary intervention (HEAT-PPCI): an open-label, single centre, randomised controlled trial. Lancet 2014; doi:10.1016/S01406736(14)60924-7 [epub ahead of print].

21 Schulz S, Richardt G, Laugwitz KL, Morath T, Neudecker J, Hoppmann P, et al. Prasugrel plus bivalirudin vs. clopidogrel plus heparin in patients with ST-segment elevation myocardial infarction. Eur Heart J 2014;35:2285-94.

22 Windecker S, Kolh P, Alfonso F, Collet JP, Cremer J, Falk V, et al. 2014 ESC/EACTS guidelines on myocardial revascularization: The Task Force on Myocardial Revascularization of the European Society of Cardiology (ESC) and the European Association for Cardio-Thoracic Surgery (EACTS) developed with the special contribution of the European Association of Percutaneous Cardiovascular Interventions (EAPCI). Eur Heart J 2014;35:2541-619.

Accepted: 09 September 2014

\section{Cite this as: BMJ 2014;349:g6419}

This is an Open Access article distributed in accordance with the Creative Commons Attribution Non Commercial (CC BY-NC 4.0) license, which permits others to distribute, remix, adapt, build upon this work non-commercially, and license their derivative works on different terms, provided the original work is properly cited and the use is non-commercial. See: http://creativecommons.org/licenses/by-nc/4.0/. 


\section{What is already known on this topic}

In patients with ST segment elevation myocardial infarction undergoing primary percutaneous coronary intervention (PCI), unfractionated heparin, low molecular weight heparin (LMWH), fondaparinux, and bivalirudin are all anticoagulant treatment options

The relative efficacy and safety of these agents have not been well defined to provide an hierarchy of treatments

\section{What this study adds}

Among the currently used anticoagulants for primary $\mathrm{PCI}$, LMWH plus glycoprotein Ilb/Illa inhibitor and unfractionated heparin plus glycoprotein Ilb/llla inhibitor were the most efficacious with the lowest ischemic rates but increased bleeding, whereas bivalirudin was safest with lowest bleeding rate at the expense of an increase in ischemic outcomes

\section{Table}

Table 1/ Evidence based considerations for anticoagulant choice during primary percutaneous coronary intervention for patients with ST segment elevation myocardial infarction

\begin{tabular}{|c|c|c|c|c|c|}
\hline \multirow[b]{2}{*}{ Anticoagulant } & \multirow{2}{*}{$\begin{array}{l}2013 \text { ACC-AHA } \\
\text { guidelines }\end{array}$} & \multirow{2}{*}{$\begin{array}{l}2014 \text { ESC } \\
\text { guidelines }\end{array}$} & \multicolumn{2}{|c|}{ Ranking for efficacy or safety } & \multirow[b]{2}{*}{ Considerations for current practice } \\
\hline & & & MACE & Major bleeding & \\
\hline \multirow[t]{2}{*}{$\begin{array}{l}\text { Unfractionated heparin } \\
+ \text { GPI }\end{array}$} & \multirow[t]{2}{*}{ CORI } & \multirow[t]{2}{*}{ CORI } & \multirow[t]{2}{*}{ 2nd } & \multirow[t]{2}{*}{4 th } & $\begin{array}{l}\text { Likely worse bleeding with newer } \mathrm{P}_{2} \mathrm{Y}_{12} \\
\text { inhibitors }\end{array}$ \\
\hline & & & & & $\begin{array}{l}\text { Bleeding risk somewhat mitigated with } \\
\text { transradial procedure }\end{array}$ \\
\hline \multirow[t]{2}{*}{ LMWH + GPI } & \multirow[t]{2}{*}{ None } & \multirow[t]{2}{*}{ COR Ila } & \multirow[t]{2}{*}{1 st } & \multirow[t]{2}{*}{ 3rd } & $\begin{array}{l}\text { Likely worse bleeding with newer } \mathrm{P}^{2} \mathrm{Y}_{12} \\
\text { inhibitors }\end{array}$ \\
\hline & & & & & $\begin{array}{l}\text { Bleeding risk somewhat mitigated with } \\
\text { transradial procedure }\end{array}$ \\
\hline Unfractionated heparin & CORI & CORI & 4th & 2nd & $\begin{array}{l}\text { Likely improved MACE with newer } \mathrm{P} 2 \mathrm{Y}_{12} \\
\text { inhibitors but may negate bleeding advantage }\end{array}$ \\
\hline \multirow[t]{2}{*}{ Bivalirudin } & CORI & \multirow[t]{2}{*}{ COR Ila } & \multirow[t]{2}{*}{ 3rd } & \multirow[t]{2}{*}{1 st } & \multirow{2}{*}{$\begin{array}{l}\text { Likely improved MACE with newer P2Y } \\
\text { inhibitors but may negate bleeding advantage }\end{array}$} \\
\hline & $\begin{array}{c}\text { Preferred over } \\
\text { unfractionated heparin + } \\
\text { GPI in those at high risk of } \\
\text { bleeding (COR Ila) }\end{array}$ & & & & \\
\hline Fondaparinux & COR III & COR III & 5 th & 5th & $\begin{array}{l}\text { Should not be recommended based on } \\
\text { current data }\end{array}$ \\
\hline
\end{tabular}

ACC-AHA = American College of Cardiology Foundation and American Heart Association. ESC $=$ European Society of Cardiology. MACE $=$ major adverse cardiovascular event. $\mathrm{COR}$ = class of recommendation. $\mathrm{GPI}=$ glycoprotein Ilb/llla inhibitor. $\mathrm{LMWH}=$ low molecular weight heparin. 


\section{Figures}

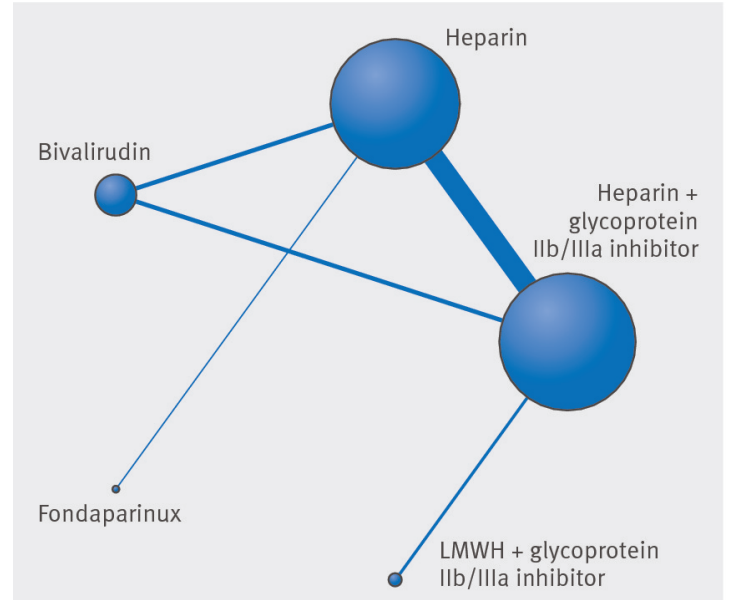

Fig 1 Network plot of treatment comparisons. Nodes and edges are weighted according to the number of studies including the respective interventions. 


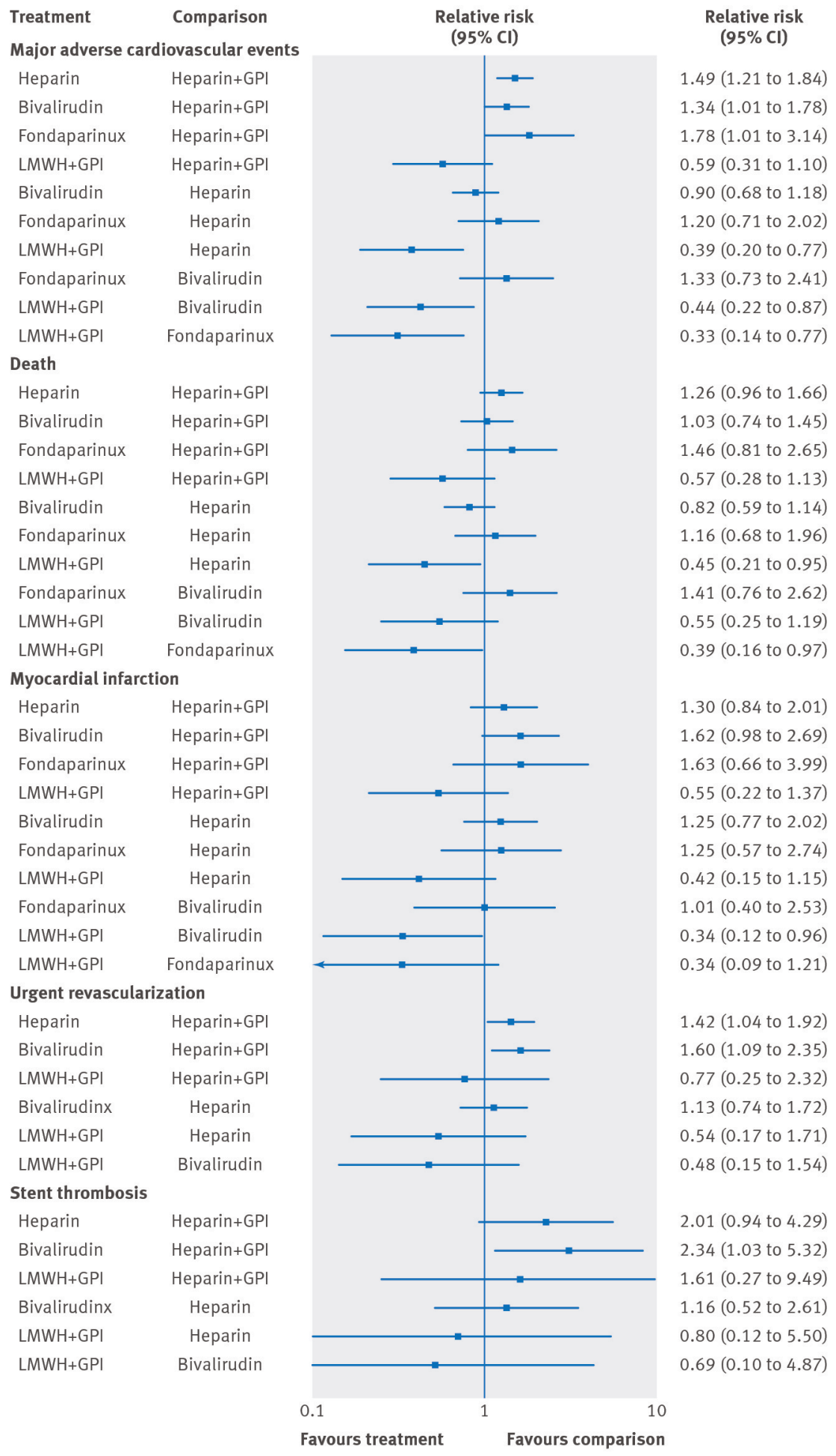

Fig 2 Comparison of various anticoagulant therapies from the mixed treatment comparison model for the outcomes of (a) major adverse cardiovascular events, $(b)$ death, $(c)$ myocardial infarction, $(d)$ urgent revascularization, and $(e)$ stent thrombosis 


\begin{tabular}{|c|c|c|c|c|}
\hline $\begin{array}{l}\text { Treatment } \\
\text { Major bleeding }\end{array}$ & Comparison & \multicolumn{2}{|c|}{$\begin{array}{c}\text { Relative risk } \\
(95 \% \mathrm{Cl})\end{array}$} & $\begin{array}{c}\text { Relative risk } \\
(95 \% \mathrm{Cl})\end{array}$ \\
\hline Heparin & Heparin+GPI & $\rightarrow$ & + & $0.82(0.59$ to 1.14$)$ \\
\hline Bivalirudin & Heparin+GPI & - & & $0.47(0.30$ to 0.74$)$ \\
\hline Fondaparinux & Heparin+GPI & & & 1.47 ( 0.48 to 4.49$)$ \\
\hline $\mathrm{LMWH}+\mathrm{GPI}$ & Heparin+GPI & & & 0.86 (0.36 to 2.07$)$ \\
\hline Bivalirudin & Heparin & $\rightarrow-$ & & 0.58 (0.37 to 0.90$)$ \\
\hline Fondaparinux & Heparin & & & 1.79 (0.62 to 5.22$)$ \\
\hline $\mathrm{LMWH}+\mathrm{GPI}$ & Heparin & & & 1.05 (0.41 to 2.69$)$ \\
\hline Fondaparinux & Bivalirudin & & & $3.10(0.97$ to 9.86$)$ \\
\hline LMWH+GPI & Bivalirudin & & & 1.82 (0.68 to 4.87$)$ \\
\hline $\mathrm{LMWH}+\mathrm{GPI}$ & Fondaparinux & & & 0.59 (0.14 to 2.43$)$ \\
\hline \multicolumn{5}{|l|}{ Minor bleeding } \\
\hline Heparin & Heparin+GPI & $\longrightarrow$ & & 0.67 (0.52 to 0.86$)$ \\
\hline Bivalirudin & Heparin+GPI & $\longrightarrow$ & & $0.56(0.43$ to 0.74$)$ \\
\hline LMWH+GPI & Heparin+GPI & & & 0.74 (0.40 to 1.38$)$ \\
\hline Bivalirudinx & Heparin & $\rightarrow$ & & 0.84 (0.63 to 1.12$)$ \\
\hline $\mathrm{LMWH}+\mathrm{GPI}$ & Heparin & & & 1.11 ( 0.57 to 2.14$)$ \\
\hline \multirow[t]{2}{*}{$\mathrm{LMWH}+\mathrm{GPI}$} & Bivalirudin & & & 1.32 (0.68 to 2.60$)$ \\
\hline & & . & 1 & \\
\hline
\end{tabular}

LMWH= low molecular weight heparin; GPI= glycoprotein IIb/IIla inhibitor

Fig 3 Comparison of various anticoagulant therapies from the mixed treatment comparison model for the outcomes of (a) major bleeding and $(b)$ minor bleeding 


\begin{tabular}{|c|c|c|c|c|c|}
\hline \multirow[b]{2}{*}{ Study } & \multicolumn{2}{|c|}{ No of events/total } & \multirow[b]{2}{*}{$\begin{array}{l}\text { Relative risk } \\
(95 \% \mathrm{Cl})\end{array}$} & \multirow[b]{2}{*}{$\begin{array}{c}\text { Weight } \\
\text { (\%) }\end{array}$} & \multirow[b]{2}{*}{$\begin{array}{l}\text { Relative risk } \\
(95 \% \mathrm{Cl})\end{array}$} \\
\hline & Bivalirudin & Comparison & & & \\
\hline \multicolumn{6}{|c|}{ Comparison $=$ Heparin+GPI } \\
\hline BRIGHT (UFH+GPI) & $37 / 735$ & $36 / 730$ & & 12.31 & $1.02(0.65$ to 1.60$)$ \\
\hline EUROMAX (UFH+GPI) & $65 / 1089$ & $28 / 649$ & & 12.96 & 1.38 (0.90 to 2.13$)$ \\
\hline HORIZONS-AMI & $98 / 1800$ & $99 / 1802$ & & 23.60 & $0.99(0.76$ to 1.30$)$ \\
\hline Subtotal & $200 / 3624$ & $163 / 3181$ & & 48.87 & \\
\hline \multicolumn{2}{|c|}{$D+L: I^{2}=0.0 \%, P=0.427$} & & & & 1.07 (0.88 to 1.32$)$ \\
\hline \multirow{2}{*}{\multicolumn{3}{|c|}{$\begin{array}{l}\mathrm{M}-\mathrm{H} \\
\text { Comparison }=\text { Heparin }\end{array}$}} & & & 1.08 (0.88 to 1.25$)$ \\
\hline & & & & & \\
\hline BRAVE-4 & $13 / 271$ & $15 / 277$ & & 5.53 & 0.89 (0.43 to 1.83$)$ \\
\hline BRIGHT (UFH) & $37 / 735$ & $42 / 729$ & & 13.07 & 0.87 (0.57 to 1.34$)$ \\
\hline EUROMAX (UFH) & 65/1089 & $33 / 460$ & & 14.28 & 0.83 (0.56 to 1.25$)$ \\
\hline HEAT-PPCI & $79 / 915$ & $52 / 914$ & - & 18.25 & 1.52 (1.08 to 2.13$)$ \\
\hline Subtotal & $194 / 3010$ & $142 / 2380$ & & 51.13 & \\
\hline \multicolumn{2}{|c|}{$D+L: I^{2}=53.8 \%, P=0.090$} & & & & 1.03 (0.74 to 1.43 ) \\
\hline \multicolumn{2}{|l|}{ M-H } & & & & 1.08 (0.87 to 1.33$)$ \\
\hline Total & $394 / 6634$ & $305 / 5561$ & & 100.00 & \\
\hline \multicolumn{2}{|c|}{$D+L: I^{2}=26.8 \%, P=0.224$} & & & & 1.07 (0.89 to 1.28$)$ \\
\hline \multicolumn{2}{|l|}{$M-H$} & & & & 1.08 (0.93 to 1.25$)$ \\
\hline \multicolumn{6}{|l|}{ Death } \\
\hline \multicolumn{6}{|c|}{ Comparison $=$ Heparin+GPI } \\
\hline BRIGHT (UFH+GPI) & $13 / 735$ & $15 / 730$ & & 8.37 & 0.86 (0.41 to 1.80$)$ \\
\hline EUROMAX (UFH+GPI) & $32 / 1089$ & $15 / 649$ & & 12.34 & 1.27 (0.69 to 2.33$)$ \\
\hline HORIZONS-AMI & $37 / 1800$ & $56 / 1802$ & $\rightarrow-$ & 26.92 & 0.66 (0.44 to 1.00$)$ \\
\hline Subtotal & $82 / 3624$ & $86 / 3181$ & & 47.63 & \\
\hline \multicolumn{2}{|c|}{$D+L: I^{2}=35.2 \%, P=0.214$} & & & & 0.85 (0.57 to 1.28$)$ \\
\hline \multicolumn{2}{|l|}{$\mathrm{M}-\mathrm{H}$} & & & & 0.82 (0.61 to 1.12$)$ \\
\hline \multicolumn{6}{|l|}{ Comparison = Heparin } \\
\hline BRAVE-4 & $7 / 271$ & $7 / 277$ & & 4.23 & $1.02(0.36$ to 2.88$)$ \\
\hline BRIGHT (UFH) & $13 / 735$ & $13 / 729$ & - & 7.48 & 0.99 (0.46 to 2.12$)$ \\
\hline EUROMAX (UFH) & $32 / 1089$ & $19 / 460$ & & 14.58 & $0.71(0.41$ to 1.24$)$ \\
\hline HEAT-PPCI & $46 / 915$ & $39 / 914$ & - & 26.07 & 1.18 (0.78 to 1.79$)$ \\
\hline Subtotal & $98 / 3010$ & $77 / 2380$ & & 52.37 & \\
\hline \multicolumn{2}{|c|}{$D+L: I^{2}=0.0 \%, P=0.558$} & & & & 0.99 (0.74 to 1.32$)$ \\
\hline \multicolumn{2}{|l|}{$M-H$} & & & & 0.99 (0.74 to 1.33$)$ \\
\hline Total & $180 / 6634$ & $164 / 5561$ & & 100.00 & \\
\hline \multicolumn{2}{|l|}{$D+L: I^{2}=0.0 \%, P=0.426$} & & d) & & 0.90 (0.73 to 1.12$)$ \\
\hline \multirow[t]{3}{*}{$M-H$} & & & 4 & & 0.91 (0.73 to 1.12$)$ \\
\hline & & & 1 & 10 & \\
\hline & & & & & \\
\hline
\end{tabular}

UFH=unfractionated heparin; GPI=glycoprotein IIb/IIla inhibitor; D+L=DerSimonian and Laird; M-H=Mantel-Haenszel test

Fig 4 Bivalirudin versus heparin with or without glycoprotein Ilb/llla inhibitor from a direct comparison analysis for the outcomes of $(a)$ major adverse cardiovascular event and $(b)$ death 


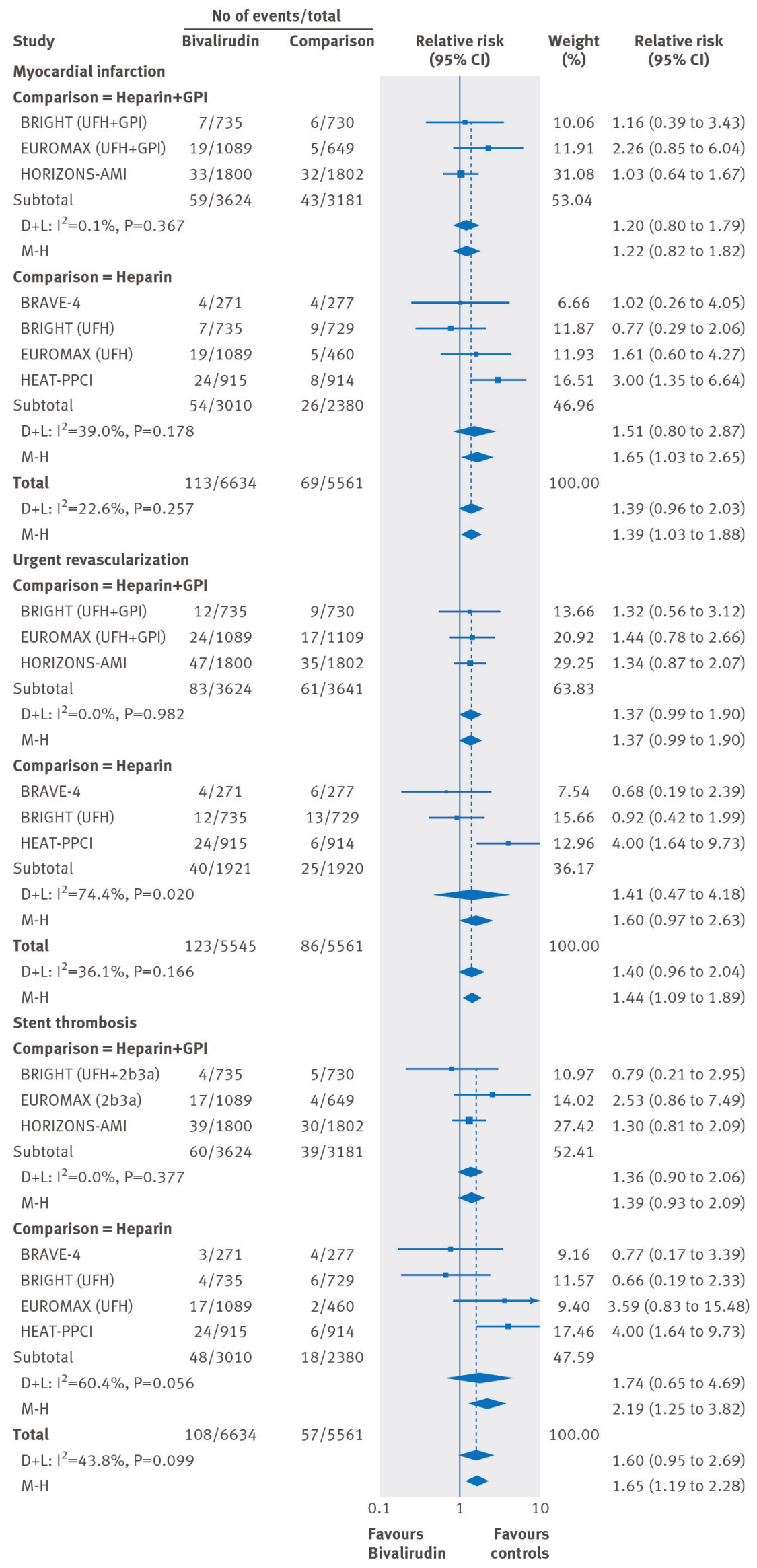

UFH=unfractionated heparin; GPI=glycoprotein Ilb/Illa inhibitor; D+L=DerSimonian and Laird; M-H=Mantel-Haenszel test

Fig 5 Bivalirudin versus heparin with or without glycoprotein Ilb/llla inhibitor from a direct comparison analysis for the outcomes of (a) myocardial infarction, (b) urgent revascularization, and (c) stent thrombosis 


\begin{tabular}{|c|c|c|c|c|c|c|}
\hline \multirow[b]{2}{*}{ Study } & \multicolumn{2}{|c|}{ No of events/total } & & & \multirow[b]{2}{*}{$\begin{array}{c}\text { Weight } \\
\text { (\%) }\end{array}$} & \multirow[b]{2}{*}{$\begin{array}{c}\text { Relative risk } \\
(95 \% \mathrm{CI})\end{array}$} \\
\hline & \multirow[t]{2}{*}{ Bivalirudin } & \multirow[t]{2}{*}{ Comparison } & \multicolumn{2}{|c|}{$\begin{array}{c}\text { Relative risk } \\
(95 \% \mathrm{Cl})\end{array}$} & & \\
\hline Comparison $=$ Heparin & & & & & & \\
\hline BRIGHT (UFH+GPI) & $4 / 735$ & $15 / 730$ & & & 7.18 & $0.26(0.09$ to 0.79$)$ \\
\hline EUROMAX (UFH+GPI) & $28 / 1089$ & $38 / 649$ & & & 18.64 & $0.44(0.27$ to 0.71$)$ \\
\hline HORIZONS-AMI & $55 / 1800$ & $91 / 1802$ & & & 23.12 & $0.61(0.44$ to 0.84$)$ \\
\hline Subtotal & $87 / 3624$ & $144 / 3181$ & & & 48.94 & \\
\hline \multicolumn{2}{|c|}{$D+L: I^{2}=17.9 \%, P=0.296$} & & & & & $0.50(0.37$ to 0.71$)$ \\
\hline \multicolumn{2}{|l|}{$\mathrm{M}-\mathrm{H}$} & & & & & 0.52 (0.40 to 0.68$)$ \\
\hline \multicolumn{7}{|l|}{ Comparison = Heparin } \\
\hline BRAVE-4 & $7 / 271$ & $8 / 277$ & & & 8.33 & $0.89(0.33$ to 2.43$)$ \\
\hline BRIGHT (UFH) & $4 / 735$ & $11 / 729$ & & & 6.86 & $0.36(0.12$ to 1.13$)$ \\
\hline EUROMAX (UFH) & $28 / 1089$ & $29 / 460$ & & & 17.81 & $0.41(0.25$ to 0.68$)$ \\
\hline HEAT-PPCI & $32 / 915$ & $28 / 914$ & & & 18.06 & 1.14 (0.69 to 1.88$)$ \\
\hline Subtotal & $71 / 3010$ & $76 / 2380$ & & & 51.06 & \\
\hline \multicolumn{2}{|c|}{$D+L: I^{2}=68.4 \%, P=0.023$} & & & & & 0.65 (0.34 to 1.22$)$ \\
\hline \multicolumn{2}{|l|}{$\mathrm{M}-\mathrm{H}$} & & & & & 0.68 (0.50 to 0.93$)$ \\
\hline Total & $158 / 6634$ & $220 / 5561$ & & & 100.00 & \\
\hline \multicolumn{2}{|c|}{$D+L: I^{2}=54.8 \%, P=0.039$} & & & & & $0.56(0.40$ to 0.79$)$ \\
\hline \multicolumn{2}{|l|}{$\mathrm{M}-\mathrm{H}$} & & $\bullet$ & & & $0.58(0.47$ to 0.71$)$ \\
\hline \multicolumn{7}{|l|}{ Minor bleeding } \\
\hline \multicolumn{7}{|c|}{ Comparison = Heparin+GPI } \\
\hline BRIGHT (UFH+GPI) & $26 / 735$ & $76 / 730$ & 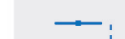 & & 15.63 & $0.34(0.22$ to 0.52$)$ \\
\hline EUROMAX & $71 / 1089$ & $123 / 1109$ & 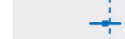 & & 19.56 & $0.59(0.44$ to 0.78$)$ \\
\hline HORIZONS-AMI & $51 / 1800$ & $82 / 1802$ & & & 17.93 & 0.62 (0.44 to 0.88$)$ \\
\hline Subtotal & $148 / 3624$ & $281 / 3641$ & & & 53.12 & \\
\hline \multicolumn{2}{|l|}{$D+L: I^{2}=62.9 \%, P=0.068$} & & 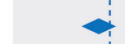 & & & 0.52 (0.37 to 0.72$)$ \\
\hline \multicolumn{2}{|l|}{$\mathrm{M}-\mathrm{H}$} & & 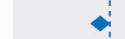 & & & 0.53 (0.44 to 0.64$)$ \\
\hline \multicolumn{7}{|l|}{ Comparison = Heparin } \\
\hline BRAVE-4 & $25 / 271$ & $20 / 277$ & & & 12.62 & 1.28 (0.73 to 2.24$)$ \\
\hline BRIGHT (UFH) & $26 / 735$ & $44 / 729$ & & & 14.64 & 0.59 (0.36 to 0.94$)$ \\
\hline HEAT-PPCI & $83 / 915$ & $98 / 914$ & & & 19.62 & 0.85 (0.64 to 1.12$)$ \\
\hline Subtotal & $134 / 1921$ & $162 / 1920$ & & & 46.88 & \\
\hline \multicolumn{2}{|c|}{$D+L: I^{2}=53.6 \%, P=0.116$} & & & & & $0.84(0.58$ to 1.21$)$ \\
\hline \multicolumn{2}{|l|}{$\mathrm{M}-\mathrm{H}$} & & & & & 0.83 (0.66 to 1.03$)$ \\
\hline Total & $282 / 5545$ & $443 / 5561$ & & & 100.00 & \\
\hline \multicolumn{2}{|c|}{$D+L: I^{2}=72.7 \%, P=0.003$} & & $\dot{\alpha}$ & & & 0.65 (0.48 to 0.86$)$ \\
\hline \multirow[t]{3}{*}{$\mathrm{M}-\mathrm{H}$} & & & $\bullet$ & & & $0.64(0.55$ to 0.74$)$ \\
\hline & & & 0.1 & & 0 & \\
\hline & & & $\begin{array}{l}\text { Favours } \\
\text { Bivalirudin }\end{array}$ & & & \\
\hline
\end{tabular}

UFH=unfractionated heparin; GPI= glycoprotein IIb/IIla inhibitor; D+L=DerSimonian and Laird; $M$-H=Mantel-Haenszel test

Fig 6 Bivalirudin versus heparin with or without glycoprotein Ilb/llla inhibitor from a direct comparison analysis for the outcomes of $(a)$ major bleeding, and $(b)$ minor bleeding

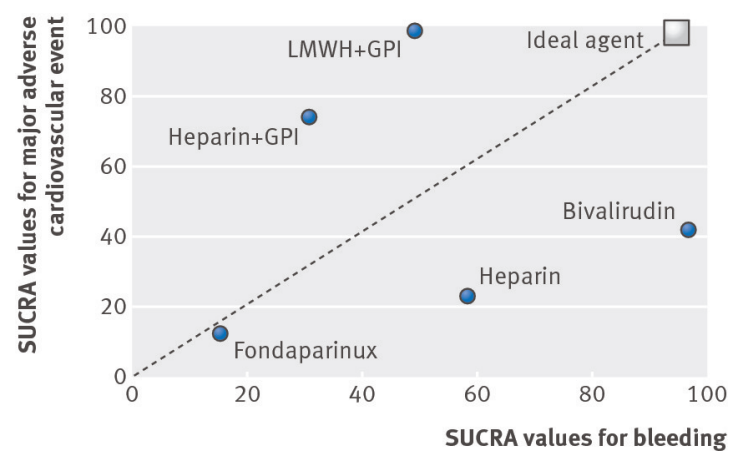

LMWH=low molecular weight heparin; GPI=glycoprotein IIb/IIla inhibitor

Fig 7 Clustered ranking plot for major adverse cardiovascular event and bleeding outcomes for various anticoagulant strategies. The higher the SUCRA (surface under the cumulative ranking curve) values, the greater the efficacy for the corresponding outcome. The hypothetical ideal agent maximizes outcomes for both ischemic and bleeding endpoints 